\title{
A Educação Contextualizada para a convivência com o Semiárido Brasileiro como uma prática emancipadora ${ }^{i}$
}

\author{
Luana Patrícia Costa Silva ${ }^{1}$, Albertina Maria Ribeiro Brito de Araújo $^{2}$, Alexandre Eduardo de Araújo ${ }^{3}$ \\ ${ }^{1}$ Universidade Federal da Paraíba - UFPB. Programa de Pós-Graduação em Educação (PPGE). Jardim Cidade \\ Universitária, Campus I, s/n. João Pessoa - PB. Brasil. luana_gca@ hotmail.com. ${ }^{2}$ Universidade Federal da \\ Paraíba - UFPB. ${ }^{3}$ Universidade Federal da Paraíba - UFPB.
}

\begin{abstract}
RESUMO. Este trabalho tem como principal objetivo elucidar práticas pedagógicas que esboçam uma relação de Educação para Convivência com o Semiárido Brasileiro, a partir da experiência da Escola Plínio Lemos - Escola da Terra, localizada no assentamento Zé Marcolino, Prata - PB. Esse processo foi consolidado frente a uma proposta metodológica de abordagem qualitativa e a partir da pesquisa participante, pautada nos estudos de Brandão (2002, 2006). As proposituras encontradas na pesquisa emergem da luta por uma escola do campo, com a proatividade das mães e se materializa frente à construção de uma escola que passa a consolidar propostas pedagógicas pautadas na Educação para Convivência com o Semiárido Brasileiro. Estas propostas são visualizadas na prática das educadoras que possibilitam um contexto educativo pautado no ensinar e aprender coletivos, por meio de intercâmbios, gincanas e contextualizações, frente à realidade dos sujeitos envolvidos no processo educativo. Desta forma, foi possível identificar ações emancipadoras que descortinam os estereótipos destinados às regiões Semiáridas e aos seus sujeitos, na medida em que passam a ressignificar suas identidades e construir uma nova concepção educativa, pautada na emancipação e na autonomia.
\end{abstract}

Palavras-chave: Educação Contextualizada, Semiárido, Educação do Campo. 


\title{
Contextualized Education for coexistence with the brazilian Semiarid as an emancipatory practice
}

\begin{abstract}
This work has as main objective to elucidate pedagogical practices that outline a relationship of Education for Living with the Brazilian Semi - arid, from the experience of the Plínio Lemos School - School of the Earth, located in the Zé Marcolino settlement, Prata - PB. This process was consolidated against a methodological proposal of a qualitative approach and from the participant research, based on the studies of Brandão $(2002,2006)$. The proposals found in the research emerge from the struggle for a rural school, with the proactively of the mother sand materializes in front of the construction of a school that starts to consolidate pedagogical proposals based on Education for Coexistence with the Brazilian Semiarid. These proposals are visualized in the practice of the educators that allow an educational context based on the teaching and collective learning, through exchanges, scan sand contextualizations, facing the reality of the subjects involved in the education al process. In this way, it was possible to identify emancipator actions that reveal the stereotypes destined to the semi-arid region sand their subjects, as they begin to resignify their identities and build a new educational conception, based on emancipation and autonomy.
\end{abstract}

Keywords: Contextualized Education, Semiarid, Rural Education. 


\section{La educación contextualizada para la convivencia con el semiárido brasileño como una práctica emancipadora}

RESUMEN. Este trabajo tiene como principal objetivo elucidar prácticas pedagógicas que esbozan una relación de Educación para Convivencia con el Semiárido Brasileño, a partir de la experiencia de la Escuela Plínio Lemos - Escuela de la Tierra, ubicada en el asentamiento Zé Marcolino, Prata - PB. Este proceso se consolidó frente a una propuesta metodológica de abordaje cualitativo y a partir de la investigación participante, pautada en los estudios de Brandão (2002, 2006). Las proposiciones encontradas en la investigación, emergen de la lucha por una escuela del campo, con la pro actividad de las madres y se materializa frente a la construcción de una escuela que pasa a consolidar propuestas pedagógicas pautadas en la Educación para Convivencia con el Semiárido Brasileño. Estas propuestas se visualizan en la práctica de las educadoras que posibilitan un contexto educativo pautado en enseñar y aprender colectivo, por medio de intercambios, gincanas $y$ contextualizaciones, frente a la realidad de los sujetos involucrados en el proceso educativo. De esta forma, fue posible identificar acciones emancipadoras que descortinan los estereotipos destinados a las regiones semiáridas ya sus sujetos, a medida que pasan a resinificar sus identidades y construir una nueva concepción educativa, pautada en la emancipación y en la autonomía.

Palabras clave: Educación Contextual, Semiárido, Educación del Campo. 


\section{Introdução}

No tocante à região nordeste do Brasil, deparamo-nos com um contexto social, político e ambiental que herda as regras de um conjunto de peculiaridades que estão inerentes à composição histórica dessa região. Sendo grande parte da área desse território composta por características semiáridas, há muito essa história toma forma, cor e sentido. Um sentido um tanto quanto distorcido da realidade existente, mas, mesmo assim, um sentido estereotipado e encarnado nas poesias, nas telenovelas, nas falas e nos livros didáticos.

O Semiárido Brasileiro há muito vem sendo de flagelados, de retirantes, de fome, seca e miséria. Essa é uma construção social que vive no imaginário descritivo dos territórios semiaridianos, que acompanha os sujeitos dessas regiões. O desconhecimento da fauna e da flora, das peculiaridades do lugar e até mesmo do povo que nele vive fez com que esse imaginário tivesse vez e voz na vida cotidiana dos sujeitos presentes em várias regiões desse território.

Esse cotidiano ou cotidianos se apresenta(m) na forma de "lugares" e o lugar de destaque aqui é o lugar da escola. A escola como berço, como articulador de forças, a escola como lugar de emancipação, de construção social, política e cultural, como ressignificadora de processos e ações. Entretanto, essa escola, que deveria ser esse berço, acontece também emergida nesse imaginário, pois ela é fruto dos sujeitos que se fazem perante a "construção de desconstruções". Desconstroem negando, negam sua fala, suas vestes, sua cultura, seu ofício. Essa negação é visualizada na condição das crianças camponesas que há muito estão inseridas em práticas educativas colonizadoras, fundadas em uma educação bancária, que, em suma, desconsideram processos locais. Desconsideram um diálogo horizontalizado, que se contrapõe à inserção de práticas, aprendizagens e conteúdos desconectados das realidades nas quais as crianças do campo estão inseridas, acontecendo, por sua vez, de forma verticalizada.

A proposta de Educação Contextualizada para a Convivência com o Semiárido Brasileiro alicerça-se nessa negação para propor que a prática educativa voltada para esses territórios se ressignifique. Ela vem propor uma nova forma de "construir descolonizando". Ela não nega, assim como faz o processo colonizador; ela agrega, ela dialoga, ampara-se na experiência vivida, no lugar habitado, para assim possibilitar processos alicerçados em aprendizagens reais e 
contextualizadas, a partir de uma esfera local. Na Educação para a Convivência com Semiárido Brasileiro, o processo de descolonização só será possível a partir da concepção da emergência de uma nova/outra racionalidade, que, por sua vez, compreenda, antes do todo, a representação de suas partes. Desta forma, é necessário apartar-se da forma colonizadora de produzir ciência, que, por sua vez, migrou para distintos âmbitos da sociedade, bem como para a escola e para os processos educativos.

É diante desses conflitos que buscamos elucidar uma experiência que surge na contramão da concepção colonizadora e vem construindo processos pautados no conhecimento para a emancipação a partir da ótica da Educação Contextualizada para a Convivência com o Semiárido Brasileiro. Assim, por meio de lutas, práticas, respeito aos saberes e produção do conhecimento, dialogaremos com uma escola que se materializa a partir da luta de mulheres-mães no Cariri da Paraíba, a Escola Plínio Lemos - Escola da Terra.

Esse artigo é um recorte de uma pesquisa cujas abordagens fazem parte de nossa dissertação de mestrado e tem como principal objetivo elucidar práticas pedagógicas que esboçam uma relação com a Educação para Convivência com o
Semiárido Brasileiro, a partir da experiência da Escola Plínio Lemos Escola da Terra.

\section{Caminhos metodológicos}

A metodologia utilizada nesse processo ancora-se nas pesquisas voltadas para o entendimento de contextos populares e de seus sujeitos, assim, esses estudos possuem raízes nas pesquisas antropológicas e etnográficas. Enquanto abordagem, o presente estudo segue uma concepção qualitativa, sendo esta compreendida por Bogdan e Biklen (1994, p. 48):

\begin{abstract}
A investigação qualitativa é descritiva. Os dados recolhidos são em forma de palavras ou imagens e não de números. Os resultados escritos da investigação contem citações feitas com base nos dados para ilustrar e substanciar a apresentação. Os dados constituem transcrição de entrevistas, notas de campo, fotografias, vídeos, documentos pessoais, memorandos e outros registros oficiais.
\end{abstract}

A descrição pontuada pelos autores aponta para a concepção dessa abordagem, porém, faz-se necessário pontuar que realizamos uma pesquisa participante, em que pudemos vivenciar o modus vivendi dos sujeitos de pesquisa, no ambiente pesquisado, emergido dos contextos e práticas desses sujeitos da investigação. A 
prática de Pesquisa Participante possui como prisma uma imersão profunda do pesquisador na realidade estudada e a indissociabilidade entre pesquisadores e sujeitos do processo de pesquisa.

Corroborando com nossas abordagens, Brandão (2006) coloca a pesquisa participante enquanto ação participante em duas situações: a primeira diz respeito à participação efetiva dos sujeitos enquanto protagonistas na pesquisa e não meros objetos. Já a segunda coloca a pesquisa participante enquanto instrumento científico, político e pedagógico de produção partilhada do conhecimento social e também é um momento de ação social.

É a partir da concepção de pesquisa participante que utilizamos, enquanto instrumentos de elaboração dos dados para subsidiar nossas análises, as entrevistas semiestruturadas e a observação participante. Compreendemos que tais abordagens se complementam e estão em harmonia uma com a outra. De acordo com Mello (2005, p. 63):

A prática da Observação Participante é um mergulho na cultura do outro, no seu habitat, para entender sua lógica, sua ordem simbólica, entrando na "teia" social que constitui as relações internas do grupo e entre os diferentes grupos ... É preciso que esteja o participantepesquisador disposto a tal e imbuído de curiosidade e de uma metodologia de registro e sistematização dessas experiências, além de um indispensável distanciamento crítico.

Por meio desses vieses e aludidos às concepções de Brandão (2006), compreendemos que a pesquisa participante nunca traz uma resposta pronta e acabada, pois estas não existem; ela aponta para reflexões e busca investigar soluções para determinadas situações e, a partir daí, possibilitar novas investigações. Como o saber não se configura enquanto algo neutro, as relações pesquisadas também não são; elas são cíclicas, mutáveis, e nenhuma abordagem vai responder, completamente, as necessidades imbricadas ali, nessas relações. Portanto, essas pesquisas trazem mais questionamentos do que respostas.

Neste sentido, daremos indícios para vários questionamentos e construções de possibilidades no campo da produção do conhecimento e da pesquisa. A ideia não é de apontar para processos prontos $\mathrm{e}$ acabados, mas de mostrar experiências, caminhos e sujeitos que constroem e reconstroem, em suas cotidianidades, os territórios da Educação do Campo e da Educação Contextualizada para a Convivência com o Semiárido Brasileiro.

\section{Pressupostos para uma educação do campo contextualizada}


Aqui na Região Nordeste

Tem riqueza de montão

Tem pé de mandacaru

E pé de urtiga que se tocar machuca a mão

Tem cabra que come palma

E pássaros que cantam canção

(Verso coletivo de crianças que fizeram parte

da pesquisa)

Brandão (2006), em sua obra "O que é Educação Popular", fez uma breve reflexão sobre a comparação do ensinar e do aprender nas relações existentes entre nossos ancestrais, os macacos superiores, ao relatar a relação da mãe amamentando o filho aconchegado ao peito, ao realçar as trocas de olhares, gestos, e do surgimento de múltiplos sentimentos, que passam pelas várias formas do ensinar e aprender, e são nessas relações de vida, sejam entre macacos (animais), sejam nas relações humanas, que as relações coletivas fluem e essas trocas entre esses sujeitos geram do pensar ao conhecer e, daí, o conhecimento simbólico de cada coisa. Então, se essas relações se estabelecem no contato, no gesto, no olhar e na magnitude de vários sentimentos, como passarem despercebidas as relações petrificadas dos modelos educacionais, que, em sua totalidade, negam essas formas de ensinar e aprender?

É nessa concepção que buscamos Freire (1987), quem enfatizou as relações estabelecidas entre educadores e educandos, as relações narradoras e dissertadoras da educação bancária, fazendo a seguinte colocação:

A narração de conteúdos por isto mesmo, tende a petrificar-se ou a fazer algo quase morto, sejam valores ou dimensões concretas da realidade. Narração ou dissertação que implica num sujeito - o narrador - e em objetos pacientes, ouvintes - os educandos (Freire, 1987, p. 33).

No que confere à concepção de educação bancária, Freire (1979) vem situar que esta se estabelece a partir de uma "consciência bancária":

O educando recebe passivamente os conhecimentos, tornando-se um depósito do educador. Educa-se para arquivar o que se deposita. Mas, o curioso é que o arquivado é o próprio homem, que assim seu poder de criar, se faz menos homem, é uma peça ... A consciência bancária "pensa que quanto mais se dá mais sabe". Mas a experiência revela que com este mesmo sistema só se formam indivíduos medíocres, porque não há estímulo para a criação (Freire, 1979, p. 19-20).

A cada palavra lida da frase de Freire, estabelecemos relações com algumas formas atuais que encontramos em nosso meio educacional. Tão jovens como sua vontade de mudança são suas palavras para o retrato da educação escolar hoje em nosso país.

De acordo com Oliveira (2009), hoje na educação escolar, possuímos um sistema de avaliação educacional global, 
que define o que e quando deve ser ensinado, o que as crianças aprendem desde os anos iniciais e assim por diante, amarrando e reduzindo a liberdade das diferentes realidades definirem suas formas e metodologias de ensino.

E, na base, como chegam essas ações amarradas a que são submetidos esses sujeitos? Elas chegam por intermédio dos livros didáticos, na negação da realidade por construção de concepções que negam seus valores, que negam sua cultura, negam suas raízes. Não que esses sujeitos não tenham direito de conhecer outras culturas e conhecer o mundo no qual eles se encontram inseridos, porém, faz-se necessário trabalhar inicialmente com questões mais pertinentes ${ }^{\mathrm{ii}}$ à realidade desses educandos. Eles devem primeiramente entender o que estão fazendo ali, o porquê de estarem ali. Torna-se bastante desmotivador eles terem uma vivência no seu dia-a-dia e entrarem em uma sala de aula, onde tudo que está fora dela passa a ser desconsiderado e, de certa forma, renegado. Complementando essa ideia, Araújo (2009) faz a seguinte pontuação:

Para o homem que faz parte de determinado contexto, será mais coerente não fugir das ações de mudança que envolve a sua comunidade, pois essas mudanças irão marcá-lo e ditar normas culturais de comportamento, que lhes podem ser mais apropriadas, se ele não for alijado do processo, se puder fazer parte da elaboração dos produtos culturais inerentes à sua realidade (Araújo, 2009, p. 60).

Essas realidades ficam ainda mais comprometidas quando estamos falando sobre comunidades rurais e/ou assentamentos, assim como acerca de pequenos centros urbanos, que sentem esses pacotes educacionais de forma mais severa. A partir dessa realidade de educação urbanizada inserida no campo, o contexto local passa a ser desconsiderado dentro das escolas, institucionalizando-se por intermédio de pacotes prontos (professores da cidade, livros didáticos urbanizados, currículos verticalizados), em que as peculiaridades dos contextos e da identidade dos sujeitos dos territórios camponeses são negadas. Respaldado nos modelos educacionais urbanizados e mediados por educadores que, por sua vez, não passam por formações voltadas para lidar com as especificidades de tais realidades, vai-se consolidando um modelo de educação bancária, cada vez mais distante dos sujeitos, imbuindo no processo educativo a concepção de um campo e de um Semiárido Brasileiro sem condições de viver.

Tal modelo, sequer dialoga com a Lei de Diretrizes e Bases da Educação (LDB), especificamente com o que é abordado em seu artigo 28: 
Art. 28 - Na oferta da Educação Básica para a população rural, os sistemas de ensino promoverão as adaptações necessárias à sua adequação, às peculiaridades da vida rural e de cada região, especialmente: I - Conteúdos curriculares e metodologias apropriadas às reais necessidades e interesses dos alunos da zona rural;

II - Organização escolar própria, incluindo adequação do calendário escolar às fases do ciclo agrícola e as condições climáticas; III - adequação a natureza do trabalho na zona rural.

O artigo inserido na LDB, para além de garantir um direito aos sujeitos do campo, possibilita que a sociedade civil reflita sobre como a Educação do Campo deveria ser tratada, o que vem a reforçar a construção de concepções mais consolidadas na Educação do Campo. Uma das conquistas nesse sentido foi a aprovação das Diretrizes Operacionais para Educação Básica nas Escolas do Campo (Resolução CNE/CEB $n^{\circ} 1$, de 3 de abril de 2002), que complementam o artigo 28 da LDB. Vejamos o que especifica o Art. $2^{\circ}$ da Resolução CNE/CEB $N^{\circ} 1$, de 3 de abril de 2002:

Art. $2^{\circ}$ Estas Diretrizes, com base na legislação educacional, constituem um conjunto de princípios e de procedimentos que visam a adequar o projeto institucional das escolas do campo às Diretrizes Curriculares Nacionais para Educação Infantil, o Ensino Fundamental e Médio, a Educação de Jovens e Adultos, a Educação Especial, a Educação Indígena, a Educação Profissional de Nível Técnico e a Formação de
Educadores em Nível Médio na Modalidade Normal.

Entretanto, a efetivação das diretrizes na prática ainda é muito deficiente. As escolas que ainda se encontram no campo estão fechando as portas e esse fato pode ser observado atualmente em todo o país. Taffarel e Munarim (2015, p. 46) apontam, ancorados nos dados do II PNERA Pesquisa Nacional sobre a Educação na Reforma Agrária - que "as escolas foram reduzidas em $31,46 \%$, ou seja, 32.512 unidades foram fechadas. Com $\mathrm{O}$ fechamento de escolas, não existe a possibilidade de enfrentamento dos gravíssimos problemas que afligem a Pátria que se quer Educadora”.

Desta forma, existem experiências que resistem a esse processo de fechamento e fortalecem a luta por uma educação do campo, embasadas na proposta de uma educação voltada para a realidade camponesa enquanto região Semiárida, com dinâmicas que se fundamentam na Educação para Convivência com o Semiárido Brasileiro, como é o caso da Escola Plínio Lemos Escola da Terra, do Assentamento Zé Marcolino - localizado na cidade de Prata, Cariri da Paraíba. Junto a esses processos, pudemos vivenciar várias dinâmicas e identificar que essas propostas de educação, voltadas para a realidade 
daquelas crianças, aconteceram a partir da sensibilidade de educadoras que, mesmo estando imersas nos processos de uma educação bancária, pois suas bases educacionais foram em escolas instituídas nestes moldes - de transferência de conteúdos-, elas vem fazendo uso de metodologias contextualizadas em suas dinâmicas na escola e estão construindo, de fato, uma Educação para a Convivência com o Semiárido Brasileiro, que surge da concepção de existir no mundo e da luta por uma escola que dê sentido ao processo de ensino e aprendizagem.

Além de se identificarem enquanto sujeitos sensíveis dentro desses processos, um ponto que colaborou para essa identificação da escola, que faz uma educação voltada para a formação de uma concepção crítica e de respeito à natureza e aos sujeitos, foi a participação de uma das mães e referência militante do Assentamento no projeto UniCampo (Universidade Camponesa), que teve início em junho de 2003 e nasceu de uma parceria que incluiu a Universidade Federal de Campina Grande (UFCG) e outras organizações camponesas e sindicais da região do Cariri paraibano. $\mathrm{O}$ principal objetivo do projeto era oferecer formações para jovens camponeses, agricultores familiares, trabalhadores semterra e para membros e lideranças de organizações, de forma a reforçar as suas capacidades de análise e de elaboração de projetos individuais e coletivos (Tonneau et al., 2008).

Outra experiência também importante para o desencadeamento desses processos foi o intercâmbio que uma das educadoras da Escola Plínio Lemos realizou, para conhecer a experiência da Escola Família Agrícola (EFA) Dom Fragoso, em Independência - CE. De acordo com Pinto e Germani (2012), “as Escolas Famílias Agrícolas têm como princípios quatro elementos: o desenvolvimento do meio; a formação integral; a Pedagogia da Alternância; e o Associativismo Local, sendo que estes estão divididos em finalidades e meios", sendo um destes meios a Pedagogia da Alternância. De acordo com Cordeiro, Reis e Hage (2011, p. 123):

A Pedagogia da Alternância,
utilizada como proposta pedagógica e
metodológica, permite que as ações
sejam refletidas no grupo, facilitando
a compreensão sobre a ação e tendo o
diálogo como instrumento de
participação. Em termos gerais, a
Pedagogia da Alternância vem se
constituindo numa proposta
pedagógica assumida pelos diversos
segmentos da organização curricular
e modalidades de ensino voltadas à
realidade dos jovens e adultos
trabalhadores que têm o campo como
espaço de vida, trabalho e produção
cultural.

A Pedagogia da Alternância, utilizada como proposta pedagógica e metodológica, permite que as ações sejam refletidas no grupo, facilitando a compreensão sobre a ação e tendo o diálogo como instrumento de participação. Em termos gerais, a Pedagogia da Alternância vem se constituindo numa proposta pedagógica assumida pelos diversos segmentos da organização curricular e modalidades de ensino voltadas à realidade dos jovens e adultos trabalhadores que têm o campo como cultural. 
Assim, imersos nesse contexto e em diálogo com essas experiências e mediante estas sensibilidades e percepções oriundas da participatividade no Projeto UniCampo, no Intercâmbio com a EFA e das vivências diárias dos camponeses e camponesas, baseiam-se os princípios e metodologias que nascem e se constituem na Escola Plínio Lemos - Escola da Terra.

É diante desse contexto que as mães passam a lutar por uma escola para as crianças do Assentamento Zé Marcolino, Prata-PB. Em uma carta, uma das educadoras relata sucintamente como se deu esse processo:

Começou então uma grande luta para construir o prédio onde seria finalmente nossa escola. Com a ajuda do projeto Dom Helder Câmara que foi nosso parceiro desde o começo, conseguiu através do FIDA o recurso para construção do prédio. Mas o recurso não foi suficiente para comprar o material necessário para construção, então nossas guerreiras entraram em ação mais uma vez, foram elas que carregaram as pedras para fazer o alicerce da escola, e se encarregaram de pedir, isso mesmo de pedir, toda ajuda para conseguir terminar a escola e ser aceita. E conseguiram. Em 2010 os estudantes tinham um ótimo espaço para estudar. Hoje em 2013 fazem 5 anos que estamos nessa luta, certos de que parte do nosso dever foi cumprido, mas que a luta continua, com todo esforço, dedicação e principalmente amor, pois como disse Paulo freire: A educação é um ato de amor, portanto, um ato de coragem (Educadora Ângela).
Vale destacar que, antes de receber o recurso para a construção da escola, uma das mães sai de sua casa e a cede para que a escola funcione e, assim, as mães se organizam, fazem a merenda, limpam e ajudam na organicidade da escola, no decorrer do ano, até a construção do prédio. Foi nesse contexto que experienciamos um ano de pesquisa-ação participante. Foi junto à escola que nasceu a necessidade de se entender como as dinâmicas vinham acontecendo junto a tais sujeitos, educadores e educandos, estes que fazem parte dos vários processos produtivos e sociais do assentamento, tanto quanto os agricultores e agricultoras.

Assim, através dessa imersão, podemos identificar os vários processos nos quais esses sujeitos estavam inseridos, com um enfoque principal na visualização de metodologias voltadas para a contextualização de conteúdos com a palma forrageira e nas práticas de convivência com o semiárido.

Os primeiros contatos junto à escola e seus sujeitos já são impactantes, por identificar as várias formas de cada um agir dentro daquele processo/espaço, por suas ações que se diferenciam de outras experiências já vivenciadas. Entretanto, quando relatamos que a escola nasce da luta como esboçado anteriormente, toda 
ação, gesto e sensibilidade de cada um passam a ser entendidos.

Inicialmente, não tem como tirar o foco de pequenas ações que acontecem na escola, como as cadeiras das crianças estarem comumente em círculos, como a diretora passar o pano na escola e estar frequentemente ajudando na merenda das crianças, junto com a merendeira. Esta, por sua vez, leva a comida e entrega a cada criança, uma a uma, conversando pacientemente com aquela, ou aquele, que não está querendo comer, com uma sensibilidade tocante. Acreditamos que os gestos e as ações da merendeira vão ao encontro do que é definido por Paulo Freire (1996, p. 50) quando ele faz a seguinte reflexão:

Atitude correta de quem se encontra em permanente disponibilidade a tocar e ser tocado, a perguntar e a responder, a concordar e a discordar. Disponibilidade à vida e a seus contratempos. Estar disponível é estar sensível aos chamamentos que nos chegam aos sinais mais diversos que nos apeiam, ao canto do pássaro, à chuva que cai ou que se anuncia na nuvem escura, ao riso manso da inocência, à cara carrancuda da desaprovação, aos braços que se abrem para acolher ou ao corpo que se fecha na recusa. É na minha disponibilidade permanente à vida a que me entrego de corpo, pensar crítico, emoção, curiosidade, desejo, que vou aprendendo a ser eu mesmo em minha relação com o contrário de mim.
É a sensibilidade da merendeira e de Paulo Freire que conseguimos identificar e comparar com as várias formas que as educadoras da Escola Plínio Lemos lidam no seu dia-a-dia com as crianças, mesmo que, algumas vezes, venham a reprimir com a fala para chamar a atenção de alguma das crianças. Percebe-se, no entanto, que essas ações e tantas outras acontecem como forma de imenso respeito, inicialmente pelo que cada um conjuga como sendo o ato de educar e de aprender mutuamente com aquelas crianças.

Esse aprender e ensinar mutuamente faz-nos recordar as colocações de Brandão (2002), quando ele enfatizou as várias formas educacionais que, partindo de estruturas que formam - colocam em formas - sujeitos para o mundo dos negócios com estímulos à competitividade, desconsiderando qualquer saber ou forma de trocas mútuas. Porém, ele fala do desafiar para uma educação que humanize esses sujeitos, da busca do conhecimento de significado, e não do conhecimento vazio, e assim enfatiza o pensar "em uma educação cujos motivos sejam a formação 'por toda a vida' de pessoas cujo destino é buscar solidariamente a felicidade" (Brandão, 2002, p. 116), que vai muito além da busca pelas relações competitivocapitalistas estabelecidas em muitos ambientes de ensino hoje. 
Essa sensibilidade ainda nos traz recordações dos momentos vivenciados junto aos sujeitos da escola Plínio Lemos, quando a educadora Ângela, em uma de nossas conversas, disse uma frase que pode vir a soar estranho para alguns, como soou - inicialmente - para nós, pelas experiências que já tínhamos vivenciados em outros processos. E assim ela disse: "Eu adoro trabalhar com multisseriado", acho que não saberia trabalhar de outra forma..." (Ângela, Camponesa e Educadora). Mas, qual o problema das turmas multisseriadas? Muitos educadores trabalham com essa forma de ensino! Que ensino? Que aprender? Que sensibilidade pode ser identificada nesse processo?

O que chama a atenção na fala da educadora e se difere de outras experiências é a realidade das classes multisseriadas em uma esfera mais abrangente. Além das várias dificuldades encontradas pelo isolamento e o pouco preparo dos educadores para lidar com tal heterogeneidade de idades, séries e ritmos de aprendizagens, muitos deles organizam suas atividades em forma de seriação, em uma visão de "ajuntamento", em que são realizadas aprendizagens e avaliações diferenciadas para cada série (Hage, 2011).

Partindo desses modos de aprendizagens estabelecidos, os educadores acabam por conduzir o ensino a partir da transferência mecânica de conteúdos repassados por meio de cópia ou transcrição do quadro, com base em livros didáticos que, em sua grande maioria, desconsideram as realidades do meio rural, e ainda, o espaço escolar é subdividido por grupos - séries, com cantos ou fileiras seriadas, "como se houvesse várias salas em uma, separadas por 'paredes invisíveis"” (Hage, 2011, p. 100).

De acordo com Arroyo (2010, p. 12):

Essas contraposições entre escola multisseriada e seriada perderam sentido. Avançamos no entendimento de que a organização seriada do conhecimento levou a uma compreensão segmentada, disciplinada, hierárquica e linear tanto dos conhecimentos quanto dos processos de ensinar-aprender. Levou e leva a deixar de fora a riqueza e complexidade que é inerente à produção do conhecimento. Sobretudo, essa organização seriada levou e leva a avaliar, aprovar e, principalmente, reprovar milhões de crianças e adolescentes, de jovens e adultos porque classificados como lentos, desacelerados, com problemas de aprendizagem nos ritmos, na sequência das séries e dos níveis escolares.

Desta forma, as escolas multisseriadas devem "transgredir a constituição identitária em que se configuram, ou seja, devem romper, superar, transcender o paradigma seriado urbano de ensino, que em sua versão precarizada se materializa hegemonicamente nas escolas rurais 
multisseriadas" (Hage, 2011, p. 107). E é justamente essa transgressão que foi e é observada nas experiências junto à escola Plínio Lemos que, à medida que horizontaliza o ensino-aprendizado, foge da lógica de "ajuntamento e transferência mecânica" enfatizada por Hage (2011), configurando-se, no reinventar da escola multisseriada, entendendo o processo de ensino como o todo, de modo a construir o ensino-aprendizagem identificando as potencialidades e fragilidades de cada educando.

Para trazer essa sensibilidade que tanto nos chamou a atenção no processo, os escritos não dariam conta, pois é um sentir deles. Foram percepções dos sujeitos que a cada dia constroem a escola, e quando estamos falando desse sentir junto às turmas multisseriadas, deparamo-nos com jovens de 21 e 23 anos, educadoras, que lutaram por uma escola para seu assentamento, para suas crianças. Inicialmente, elas tinham formação de vida, na vivência das dinâmicas junto às suas famílias. Entretanto, por suas percepções de vida, elas não entendem outra forma de trabalhar com aquelas crianças que não seja com classes multisseriadas.

Esses processos são vivenciados na labuta diária das educadoras da escola onde uma das turmas é de responsabilidade de Amanda Procópio, de 21 anos, estudante do curso de Biologia, camponesa, educadora e filha de Seu Anselmo Procópio e D. Maria Procópio. A turma é formada do Maternal ao Pré II, ou seja, os anos iniciais. A outra turma fica a cargo da educadora Ângela Procópio, 28 anos, estudante do curso de Pedagogia, camponesa, educadora e também filha de Seu Anselmo Procópio e D. Maria Procópio. Ela trabalha junto às crianças que estão cursando da Alfabetização ao $5^{\circ}$ ano. Iremos nos deter em algumas características e processos junto à turma da educadora Ângela, em função do nível de seriação mais elevado e da metodologia que possuía, por envolver mais especificidades voltadas para a linha que seguia a pesquisa e ainda, em função de, na maior parte do tempo, as crianças dos anos iniciais, da educadora Amanda, serem destinadas a leituras de contos, músicas e brincadeiras.

A turma da educadora Ângela é formada por crianças que estão inseridas na faixa etária de seis a doze anos, todas residentes no assentamento ou na comunidade vizinha, conhecida como "Cabeça do Boi". A educadora tenta contemplar na forma de ensinar a "totalidade" das crianças e a turma hoje conta com apenas duas crianças, das vinte, que ainda não sabem ler, sendo esse um 
dado de extrema relevância e que com palma forrageira, algodão e materializa e reafirma na prática que a intercâmbios e tem como principal metodologia que vem sendo utilizada na característica o diálogo com o contexto.

escola (Figura 1) possui resultados

profícuos. Essas práticas pautam-se em

gincanas, aulas de campo, experimentos

Figura 1: Escola Plínio Lemos - Escola da Terra.

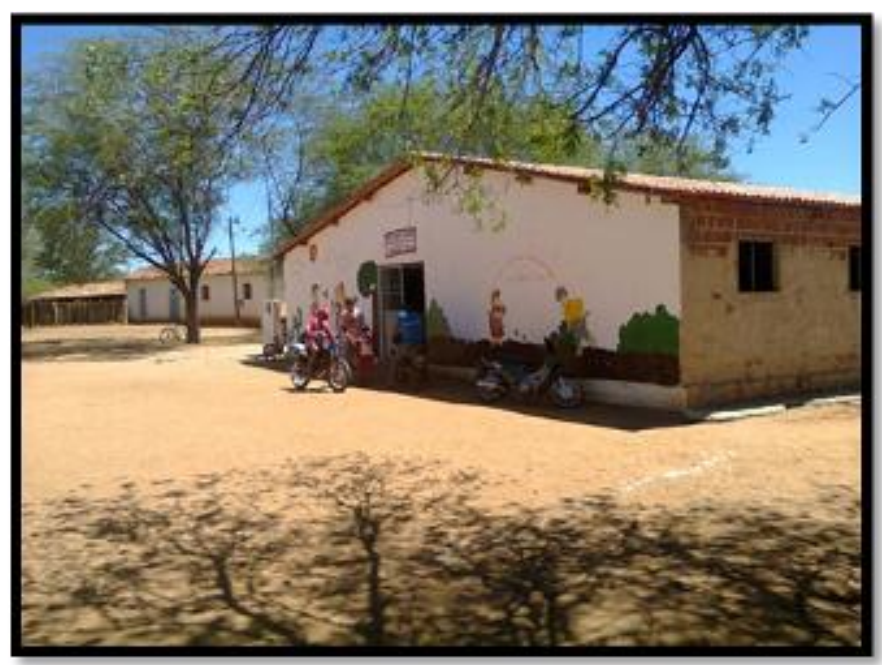

Fonte: Registro Fotográfico de campo/Assentamento Zé Marcolino/Serrote Agudo, Prata - PB, 2014.

A educadora busca trabalhar com respeito à realidade das crianças e a observação de cada um em sua singularidade. Em uma das várias conversas, Ângela disse: “Josué não sabia ler e escrever, e não aprendia de jeito nenhum! Então, eu só consegui alfabetizálo porque passei a trabalhar com ele com palavras que ele gostava como cabra, bode, barreiro. Foi aí que ele aprendeu..." (Educadora Ângela). Para Freire (1979, p. 15), “existe uma reflexão do homem face à realidade. $\mathrm{O}$ homem tende a captar uma realidade, fazendo-a objeto de seus conhecimentos. Assume a postura de um sujeito cognoscente de um objeto cognoscível".

À medida que palavras que não faziam parte de seu convívio eram compartilhadas com Josué, soavam estranhas pela não familiarização dele, daquilo ou daquela palavra verbalizada, ou escrita, que ele podia vir a não conhecer $a$ priori. Então, se existia um bloqueio de aprendizagem, desta forma, ao passar para o trabalho com palavras como a dos animais que ele ajudava ao pai a cuidar e do barreiro que ele sempre ia tomar banho com os irmãos, ele se sentiu familiarizado com as palavras, passando a dar uma 
abertura para a aprendizagem, que, em sua compreensão, apresentara-se de "forma mais significativa”. Essa é a principal essência da educação contextualizada.

Em um dos cadernos da Rede de Educação do Semiárido Brasileiro (RESAB) diz que não existe uma receita pronta como a de um bolo para a educação contextualizada, pois esta nasce das várias lutas. No assentamento, ela nasce sim da luta, e principalmente da forma de ensinar e aprender que florescem junto à necessidade, à sensibilidade, e à visão das educadoras de como seria uma forma de promover dinâmicas de aprendizagens que trouxessem em suas faces o respeito e a não negação de suas realidades enquanto sujeitos do Semiárido. E é nessa sensibilidade de Ângela, de identificar a cada dia nas crianças, em sua singularidade, a necessidade de cada uma delas, que nasce e floresce a educação contextualizada.

E, à medida que essas educadoras internalizam essas concepções, nós recordamos Freire (1996, p. 35), quando ele se colocou dizendo que "saber que devo respeitar à autonomia e à identidade do educando exige de mim uma prática em tudo coerente com esse saber". O que não se difere da realidade dessas educadoras, em que, nas várias práticas vivenciadas, foi possível identificar as inúmeras formas de educação contextualizada voltadas para a realidade do Semiárido, local de "pertencimento" dessas crianças.

No que concerne às discussões em torno de uma concepção mais consolidada de educação contextualizada, a RESAB trabalha com as discussões dos processos vivenciados nessa região. A RESAB se consolida pela construção de opções metodológicas e se situa na importância das dimensões política e pedagógica de convivência com o Semiárido.

De acordo com Mattos (2004), um dos organizadores do caderno Educação no Contexto do Semiárido Brasileiro, a escola é um dos principais espaços para a construção do conhecimento. O autor traz alguns desafios da Rede para promover uma educação contextualizada para o Semiárido Brasileiro:

\begin{abstract}
Na medida em que busca propiciar uma reflexão no e sobre o universo escolar que viabilize um novo diálogo sobre a relação sociedade e natureza; que junto ao fio do novo paradigma para aprender, reaprender a viver e conviver no semiárido; que crie e recrie novos significados que possam contribuir com a melhoria da qualidade de ensino e do sistema educacional e propicie $\mathrm{o}$ reconhecimento da identidade/destino comum do homem tanto a nível local/regional como planetário (Mattos, 2004, p. 25).
\end{abstract}

Essas concepções que permeiam a RESAB enquanto espaço de diálogo sobre 
tal temática não foram discutidas com as educadoras da escola Plínio Lemos. Em esfera de formação, essas educadoras como tantas outras não têm formação continuada $^{\text {iv }}$ em consonância com tais dinâmicas, à da Convivência com o Semiárido. Entretanto, esses desafios são vistos e enfrentados diariamente nas percepções delas em suas salas de aula e nas várias e várias formas de ensino e aprendizagem que vão sendo desenhadas, seja na música de Luiz Gonzaga que enfatiza as belezas do lugar, que é trabalhada por Ângela, seja nos desenhos de mandacaru que Amanda leva para suas crianças pintarem.

É nessa não negação do lugar enquanto espaço de legitimidade do outro (educando) que a escola vem trabalhando e se afirmando, e foram nessas vivências que foi possível identificar os processos de contextualização. Se não existe uma receita pronta, como explicar o que deve ser educação contextualizada e identificarmos essas formas dentro do processo junto a essas educadoras?

\section{O livro Educação no Contexto do} Semiárido Brasileiro $^{\mathrm{v}}$ traz a discussão no olhar de vários estudiosos sobre a temática, de modo que é possível identificar que a educação contextualizada nasce a partir do desenvolvimento de várias experiências que têm sido possíveis graças ao trabalho de "várias organizações não governamentais, pastorais sociais, igrejas e movimentos sociais, que passaram a apoiar e socializar iniciativas para a convivência mais harmônica com o ecossistema dessa região, referenciando e promovendo uma nova cultura e uma nova relação com os recursos naturais" (Braga, 2004, p. 27).

Esses sujeitos são os que fazem, a cada dia, acontecer à construção de novas formas de ensinar e aprender, pautadas nas sensibilidades dos vários escritos de Paulo Freire e outros autores e atores que dialogam nesse viés, e assim, tem-se construído concepções da pedagogia embasadas no respeito e na singularidade de cada espaço e de cada sujeito. Braga (2004, p. 29) ainda complementa:

Temos observado que essas
experiências evidenciam, através das
práticas, vivências e iniciativas de
seus protagonistas, um grande e rico
potencial educativo que precisa ser
conhecido, considerado e valorizado
pelo Estado e pela sociedade, porque
são portadoras de novos sentidos e
significados, de mudança que
apontam para uma nova relação com
o meio ambiente e um novo modelo
de desenvolvimento, sustentando na
solidariedade, na compaixão e no
cuidado com as pessoas e com a
natureza.

Não é uma receita; são receitas. E elas vêm vislumbradas nas várias vivências dos sujeitos que fazem o Semiárido. Ademais, a essas receitas são inseridos 
novos ingredientes e uma nunca é igual à outra. Elas acontecem nas várias práticas cotidianas e, à medida que acontecem e são conhecidas, passam a ser incorporadas às várias discussões, como as da RESAB, para construção de metodologias consolidadas que vão dando forma a conceitos e princípios para a Educação Contextualizada para a Convivência com o Semiárido Brasileiro.

Assim, esses conceitos e princípios brotam dos educadores, dos camponeses, de suas sensibilidades e percepção de respeito, à medida que se doam e recebem do meio em que vivem, construindo assim suas identidades enquanto "sujeitos semiaridianos" e desconstruindo os estereótipos de um espaço pobre, seco e sem vida, à medida que dão vida a ele nos vários processos de participação e diálogo.

Cada momento de participação no processo junto a esses sujeitos trazia-nos mais e mais riquezas de aprendizagens e respeito. Um deles foi se deparar com Ângela mudando o local da aula para debaixo dos pés de algaroba (Prosopisjuliflora).

Chegando de surpresa, ficamos observando como se dava toda aquela aula ao ar livre. Tratava-se de uma gincana, na qual participavam dois grupos, os meninos e as meninas e a educadora era a mediadora, realizando algumas brincadeiras e fazendo alguns questionamentos, tais como:

Qual a vegetação predominante na nossa região? O que significa o nome Caatinga? Cantem uma música que na letra tenha o nome Sertão? Cite o nome de três plantas do Bioma Caatinga ${ }^{\text {vi }}$ ? (Educadora Ângela).

Outro momento que apresenta resultados do processo pedagógico que vem acontecendo na escola se esboça em desenhos, elaborados pelas crianças, durante a oficina sobre a palma forrageira (Opuntia fícus indica), suporte forrageiro muito presente na comunidade. Na figura 2, observa-se o resultado desse processo e como as crianças enxergam o ambiente e se enxergam no contexto em que vivem.

Figura 2: Desenho elaborado por um dos educandos durante a oficina de desenhos promovida pelo projeto "Aprendendo com a Palma Forrageira". 


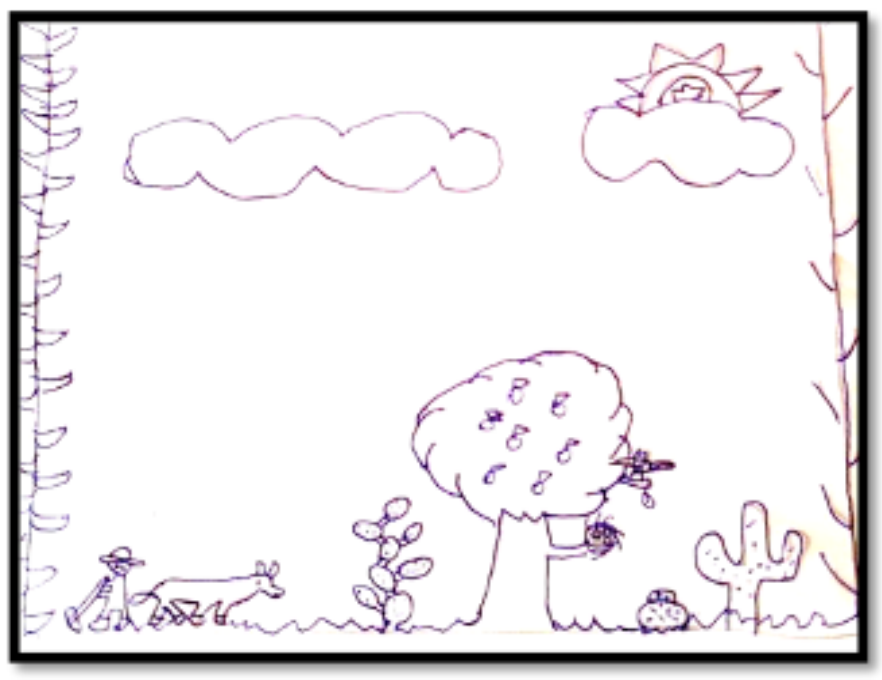

Fonte: Registro Fotográfico de campo/Assentamento Zé Marcolino/Serrote Agudo, Prata - PB, 2014.

Inserir o contexto não é apenas o simples fato de trazer as questões pertinentes à realidade das crianças, mesmo sendo concebido como um fator de extrema relevância, porém, estamos a falar a respeito do todo, do conjunto no qual acontecem esses processos. E para deixar mais nítido o que seria esse todo, recordamo-nos da fala de Brandão (2002), que, em uma de suas obras, colocou-se a respeito da educação face a face, fazendo a seguinte afirmação:

Gestos ... são trocas, onde os significados do saber chegam a mim entremeados com os afetos da emoção que ao próprio significado do que é dito dão o sentido profundo no modo como aquilo foi dito. $\mathrm{O}$ momento do encontro, o relacionamento pessoal, interpessoal, face a face, corpo-a-corpo, olhosnos-olhos e coração-com-coração (Brandão, 2002, p. 203).

É sobre essas relações que estamos falando; foram estas vivenciadas e presenciadas na relação educadora e educandos. Não são meros conteúdos dentro de um contexto, mas sim várias trocas de saberes de um contexto dentro das relações face a face desses sujeitos, estes que sentem e amam o que fazem, não por mera imposição de um sistema, mas por prazer de se sentirem fazendo e sendo parte dos vários processos que vivenciam.

Quando a educadora pede: "cantem uma música que na letra tenha o nome Sertão", existe todo um sentido de pertencimento ao lugar, de valorização da cultura, de quebra de estereótipos. À medida que as crianças cantam "lá no meu pé de serra, deixei ficar meu coração, ai que saudade eu tenho, eu vou voltar pro meu Sertão ${ }^{\text {viì, }}$, demonstrando a saudade do sertanejo do seu lugar, de como é bom voltar para suas origens, tais formas de aprender e ensinar denotam todo um aparato de valorização à cultura e à Região Semiárida; é uma ressignificação e 
valorização da identidade das crianças, de seus pais e avós, é um processo endógeno, no entanto, num bom sentido, ou seja, de construção e respeito à cultura e à natureza locais.

As educadoras estão em sintonia com Malvezzi (2007, p. 08), quando o autor situa que o "Semiárido não é apenas clima, vegetação, solo, sol ou água. É povo, música, festa, arte, religião, política $\mathrm{e}$ história. É processo social. Não se pode compreendê-lo de um ângulo só". E é nessa perspectiva que os que fazem a escola vêm trabalhando, de não ver o Semiárido como lugar de atraso, de seca e de pobreza, como há muito vem sendo estereotipado esse território, mas sim, sob a ótica da identificação dos aspectos da criação de possibilidade de conviver de forma harmoniosa nessa região, respeitando os limites naturais do ambiente e traçando estratégias de como viver e conviver com a natureza e suas potencialidades e especificidades.

\section{Considerações finais}

No percurso desta pesquisa, pudemos compreender como os processos escolares vinham acontecendo, no que concerne às práticas de contextualização de conteúdos junto aos educandos e educadores da escola Plínio Lemos - Escola da Terra. Foi possível, a partir desse contexto, identificar a experiência de educação contextualizada para a Convivência com o Semiárido Brasileiro, encontrada na escola do Assentamento Zé Marcolino, onde pudemos identificar e vivenciar esses processos nas várias formas de educar contextualizando, encontrando também os indícios das pedagogias críticas e os diálogos junto às concepções Freireanas de mundo. Ademais, pudemos visualizar processos de uma educação que mesmo nascendo em meio a precárias situações estruturais, estes tornam-se invisibilizados pela luta e força das mães que construíram e lutaram pela escola. Não estamos desviando com isso o olhar para as várias dificuldades enfrentadas, porém, queremos que seja entendível que a luta nasce justamente junto a essas dificuldades.

Junto à Escola, foi observado como se dá o ensinar e o aprender, como estes se entrelaçam e se formam nas dinâmicas das educadoras, como as formas de contextualização são rotineiras frente às práticas pedagógicas. Pudemos identificar ainda, nesse contexto, que os processos externos às realidades escolares das crianças são determinantes dentro do ambiente escolar, na medida em que, partindo de formas de ensinar que englobam o meio em que as crianças estão inseridas, respeitam valores e 
aprendizagens que são inerentes aos processos de educação não escolar, valorizando assim as identidades camponesas das crianças.

\section{Referências}

Araújo, A. M. R. B. (2009). Práticas de intervenção social em escolas rurais: uma iniciativa para o fortalecimento de escolas do campo na Paraíba. (Dissertação de Mestrado). Universidade Federal da Paraíba, Paraíba.

Arroyo, G. M. (2010). Escola: terra de direito. In Antunes-Rocha, M. I., \& Hage, S. M. Escola de direito: reinventando a escola multisseriada (pp. 9-14). Belo Horizente: Autêntica Editora.

Bogdan, R., \& Biklen, S. (1994). Investigação qualitativa em educação: Uma introdução à teoria e aos métodos. Portugal: Editora Porto.

Braga, O. R. (2004). Educação e convivência com o Semiárido: uma introdução aos fundamentos do trabalho político-educativo no semiárido brasileiro. In Kuster, A., \& Mattos, B. H. O. M. A educação no contexto do semiárido brasileiro (pp. 27-46). Fortaleza, CE: Fundação Konrad Adenauer.

Brandão, C. R. (2002). A educação popular na escola cidadã. Petrópolis: Editora Vozes.

Brandão, C. R., \& Streck, D. R. (2006). Pesquisa Participante: o saber da partilha. Aparecida: Ideias \& Letras.

Cordeiro, G. N. K., Reis, N. S., \& Hage, S. M. (2011). Pedagogia da Alternância e seus desafios para assegurar a formação humana dos sujeitos e a sustentabilidade do campo. Em Aberto, 24(85), 115-125.
Ferreira, A. B. H. (2000). Mini-Aurélio Século XXI Escolar: o minidicionário da língua portuguesa. Rio de Janeiro: Editora Nova Fronteira.

Freire, P. (1979). Educação e mudança. Rio de Janeiro, RJ: Editora Paz e Terra.

Freire, P. (1987). Pedagogia do Oprimido. Rio de Janeiro, RJ: Editora Paz e Terra.

Freire, P. (1996). Pedagogia da Autonomia: Saberes Necessários à Prática Educativa. São Paulo, SP: Editora Paz e Terra.

Hage, S. M. (2011). Por uma escola do campo de qualidade social: transgredindo o paradigma (multi)seriado de ensino. Em Aberto, 24(85), 97-113.

Kuster, A., \& Mattos, B. H. O. M. (2004). A educação no contexto do semiárido brasileiro. Fortaleza: Fundação Konrad Adenauer.

Lei n. 9.394, de 20 de dezembro de 1996. (1996, 23 de dezembro). Estabelece as Diretrizes e Bases da Educação Nacional. Diário Oficial da União, seção 1.

Malvezzi, R. (2007). Semiárido - uma visão holística. Brasília, DF: CONFEA Superintendência de Comunicação e Marketing.

Mattos, B. H. O. M. (2004). Introdução. In Kuster, A., \& Mattos, B. H. O. M. A educação no contexto do semiárido brasileiro (pp. 27-46). Fortaleza, CE: Fundação Konrad Adenauer.

Mello, M. (2005). Pesquisa participante e educação popular: da intenção ao gesto. Porto Alegre, RS: Editora Ísis - IPPOA Instituto Popular Porto Alegre.

Oliveira, I. B. (2009). Currículo em tempos de globalização: Desigualdades, diferenças e exclusões. In Pereira, M. Z. C., Carvalho, 
M. E. P., \& Porto, R. C. C. (Org.). Globalização, Interculturalidade e currículo na cena escolar. Campinas, SP: Alínea Editora.

Pinto, M. P. A., \& Germani, G. I. (2012). Escola Família Agrícola: um modelo auto gestionário? In Anais do XXI Encontro Nacional de Geografia Agrária (pp. 1-14), Uberlândia, MG.

Resolução CNE/CEB n. 1 (2002, 3 de abril). Institui Diretrizes Operacionais para a Educação Básica nas Escolas do Campo. Recuperado de: http://portal.mec.gov.br/escola-degestores-da-educacao-basica/323secretarias-112877938/orgaos-vinculados$\underline{\text { 82187207/13200-resolucao-ceb-2002 }}$

Taffarel, C. Z., \& Munarim, A. (2015). Pátria educadora e fechamento de escolas do campo: o crime continua. Revista Pedagógica, 17(35), 41-51.

Tonneau, J. P., Caniello, E. S., Sabourin, E., Leal, F., Duqué, G., \& Orós, J. (2008). Universidade Camponesa no Brasil Documento técnico e avaliação do $1^{\circ}$ ciclo da UNICAMPO. Campina Grande, PB.

i Este trabalho é recorte de uma pesquisa de
Mestrado avaliada e aprovada pelo Comitê de ética em 14 de setembro de 2013.

ii Corroboramos com a definição do minidicionário Aurélio: Pertinente adj2g. 1. Relativo, concernente, pertencente (Ferreira, 2000).

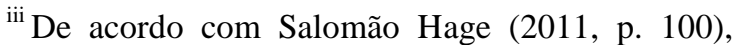
"Nas escolas multisseriadas, um único professor atua em múltiplas séries concomitantemente, reunindo, em algumas situações, estudantes da pré-escola e dos anos iniciais do ensino fundamental em uma mesma sala de aula".

${ }^{\text {iv }}$ Existem algumas formações anuais que, de acordo com as educadoras, "são muito superficiais". Ressaltamos que é de dever das instituições governamentais (Município e Governo do Estado) promoverem essas formações contínuas para os professores de escolas públicas, estando essas formações pautadas nas Diretrizes Operacionais para a Educação básica nas escolas do Campo.

${ }^{v}$ Livro este que foi resultante da I Conferência Estadual de Educação Contextualizada para a Convivência com o Semiárido no Ceará, realizada em 2003, de autoria de Kuster e Mattos (2004).

${ }^{\text {vi }}$ Aos poucos, vai se introduzindo nos trabalhos acadêmicos e textos a diferenciação de que Caatinga com " $\mathrm{C}$ " maiúsculo se refere ao Bioma e caatinga com "c" minúsculo se refere à principal vegetação do Bioma Caatinga.

vii Trecho da música "No meu pé de Serra" de autoria de Humberto Cavalcanti Teixeira e interpretada por Luiz Gonzaga.

Recebido em: 24/07/2017

Aprovado em: 11/10/2017

Publicado em: 15/12/2017

Como citar este artigo / How to cite this article / Como citar este artículo:

APA:

Silva, L. P. C., Araújo, A. M. R. B., \& Araújo, A. E. (2018). A Educação Contextualizada para a convivência com o Semiárido Brasileiro como uma prática emancipadora. Rev. Bras. Educ. Camp., 3(1), 104-125.

ABNT:

SILVA, L. P. C.; ARAÚJO, A. M. R. B.; ARAÚJO, A. E. A Educação Contextualizada para a convivência com o Semiárido Brasileiro como uma prática emancipadora. Rev. Bras. Educ. Camp., Tocantinópolis, v. 3, n. 1, p. 104-125, 2018.

\section{ORCID}

Luana Patrícia Costa Silva

http://orcid.org/0000-0002-7949-0975

Albertina Maria Ribeiro Brito de Araújo
(iD) http://orcid.org/0000-0003-1357-1366

Alexandre Eduardo de Araújo

http://orcid.org/0000-0002-1422-9864 